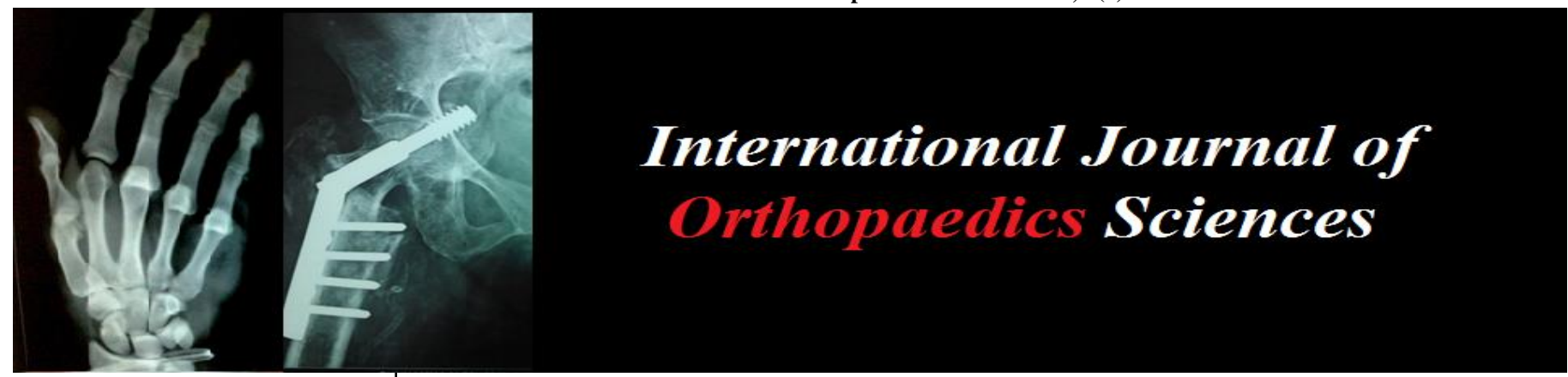

E-ISSN: 2395-1958

P-ISSN: 2706-6630

IJOS 2020; 6(3): 37-45

(C) 2020 IJOS

www.orthopaper.com

Received: 25-05-2020

Accepted: 27-06-2020

\section{Nikesh Panchbhai}

Department of Orthopaedics,

Bokaro General Hospital

Bokaro, Jharkhand, India

\section{Kumar Satyam}

Department of Orthopaedics, Bokaro General Hospital, Bokaro, Jharkhand, India

\section{Deepak Kumar}

Department of Orthopaedics, Bokaro General Hospital,

Bokaro, Jharkhand, India

\section{Narendra Karsh}

Department of Orthopaedics,

Bokaro General Hospital,

Bokaro, Jharkhand, India

\section{Ganesh Biruly}

Department of Orthopaedics,

Bokaro General Hospital,

Bokaro, Jharkhand, India

\section{Birendra Kumar}

Department of Orthopaedics, Bokaro General Hospital,

Bokaro, Jharkhand, India
Corresponding Author: Nikesh Panchbhai

Department of Orthopaedics, Bokaro General Hospital, Bokaro, Jharkhand, India

\section{To evaluate outcomes of various managements in lumbar prolapsed intervertebral disc and factors affecting the outcomes}

\author{
Nikesh Panchbhai, Kumar Satyam, Deepak Kumar, Narendra Karsh, \\ Ganesh Biruly and Birendra Kumar
}

DOI: https://doi.org/10.22271/ortho.2020.v6.i3a.2174

\begin{abstract}
Background: Backache is a disease of antiquity and has tormented lives of innumerable individual of mankind. At some point during their lifetime, about $80 \%$ of adults can be expected to experience low backache. Its point prevalence is about $30 \%$. By the age of 30 years, almost half of adults have experienced a substantive episode of low backache.

Materials and Methods: 85 patients with lumbar prolapsed intervertebral disc where selected between April 2018 to April 2019 with taking inclusion and exclusion criteria into account. 42 patients were undergone conservative treatment, 26 patients were given epidural steroid injection, 17 patients were undergone surgical (discectomy) treatment. Observation in all three groups were analyzed and compared. Results: Patients were evaluated at post op 15 days, 1 month, 3 months and 6 months with respect to previous examination findings short term outcome over a period of six months, good (60-80\% improvement in ODI) to excellent (> 80\% improvement in ODI) outcome is seen in $94 \%$ of surgically treated patients, whereas only $81 \%$ of patients treated with epidural steroid were to having good to excellent results but in conservatively treated group only $12 \%$ of patients had good to excellent outcome. Around $88 \%$ of conservatively treated patients had fair outcome.

Conclusion: Short term outcome of discectomy for PIVD is favorable as compared to conservative treatment. Epidural steroid offers promise for temporary relief with many patient requiring repeat injections at variable time interval.
\end{abstract}

Keywords: Backache, PIVD, epidural steroid, ODI score, discectomy

\section{Introduction}

At some point during their lifetime, $60 \%$ to $80 \%$ of adults can be expected to experience low back pain. The annual incidence of back pain in adults is $15 \%$, and its point prevalence is about $30 \%{ }^{[1]}$. By the age of 30 years, almost half of adults have experienced a substantive episode of low back pain ${ }^{[2]}$ Almost $(80 \%)$ of all individuals at some point of their lives suffer from incapacitating low back ache ${ }^{[3]}$. The study of Dr. Sasi Kuppuswamy et al. (2017) ${ }^{\text {[4] }}$ observed that $32.7 \%$ had degenerated discs.

\section{Material and Methods}

A prospective study was carried out on 85 patients of prolapsed lumbar intervertebral disc attending the Emergency and OPD of Orthopedics at Bokaro General Hospital, Jharkhand from April 2018 to April 2019. 42 patients were undergone conservative treatment, 26 patients were given epidural steroid injection, 17 patients were undergone surgical (discectomy) treatment. Patients were followed up immediately, after 15 days, 1 month, 3 months, 6 months after conservative, epidural steroid and after surgical treatment (disectomy). Patients pain monitor using visual analogue pain scale, Oswestry disability index ${ }^{[5]}$ and Roland Morris Questionnaires ${ }^{[6]}$ at each follow up. Information on gender, age, occupation etc. was recorded for these patients. 
Table 1: Inclusion and exclusion criteria's taken in the present study

\begin{tabular}{|l|l|}
\hline Inclusion criteria & Exclusion criteria \\
\hline All patients in the age group of 18 to 50 yrs with prolapse of & Patients with intervertebral disc prolapse associated with \\
lumbar intervertebral disc, with clinical symptoms and signs, & - Structural scoliosis, \\
and radiological evidence & - Spondylolysthesis \\
& - Congenital anomalies \\
& - Developmental dysplasia \\
& - Infections of spine specific or nonspecific \\
& - Cauda Equina syndrome \\
& - Failed back syndrome \\
& - Disc herniations at multiple levels \\
& - Tumors of lumbar spine \\
\hline
\end{tabular}

Conservative Treatment: For the great majority of the patients with backache accompanied by radiation of pain or neurological signs or gross plain $\mathrm{x}$-ray abnormalities. Conservative therapy may be indicated. The essence of conservative treatment in the acute stage is rest to the affected spine, total relief from weight bearing, analgesics and reassurance.

Duration of conservative treatment: 6 to 8 weeks or 2 months $[7,8]$

Epidural injection: The epidural injection of a combination of long acting steroid methyl-prednisolone acetate (DepoMedrol) [a dose may vary from 80 to $120 \mathrm{mg}$ with an epidural anesthesia $\{1 \%$ lidocaine $\}$ was given for symptomatic treatment of discogenic back pain.

\section{Indication for epidural steroid injection}

There has been no scientific support for the use of epidural steroids in the treatment of acute disc rupture. Occassionaly a situation presents where more aggressive treatment is indicated, but circumstances prohibit such a step. These include a pregnant woman with sciatica, a student heading into a few weeks of examinations, an elderly patient who wishes to avoid surgery, and a key athlete entering into a key game. In these situations, epidural cortisone injection might settle symptoms to a tolerable level. Except for pregnancy, epidural steroid (e.g. prednisone in a decreasing dose), provided there are no contraindications. It is likely that epidural injections of cortisone will offer short term relief, with recurrence of symptoms probable, and a more definitive surgical decision will be required ${ }^{[9]}$

Surgical Proceedure: After general anesthesia is induced, patient is put prone over spinal frame (Relton and Hall frame). A midline skin incision over spinous process centering the affected disc level is put extending down into the subcutaneous tissue, lumbodorsal fascia and supraspinous ligament. Subperiosteal dissection is carried out and muscles are stripped from spine and laminae of vertebrae from distal to proximal on side of spines processes. Spinous process of affected vertebrae excised. A rent made in midline, ligamentum flavum is removed with help of kerrison rongeur.
Shelving portion of ligamentum flavum is removed carefully until dura is exposed, protecting dura part of lamina excised piecemeal, so nerve root is brought into view. As the nerve root is held medially with help of dural retractors the herniated disc is brought into view. An incision is made over posterior longitudinal ligament and annulus fibrosus. Nucleus pulposus removed piecemeal with disc forceps. Wound is closed in layers following complete haemostasis with suction drain in situ.

\section{Postoperative management}

Patient is allowed to turn (with no twisting of spine) in bed to select position of comfort. Parental antibiotics are given for first five days after surgery followed by oral antibiotics in addition to analgesics and anti-inflammatory drugs until sutures are removed. Drain removed after 48 hours, and sutures removed after 2 weeks. Back exercises started 4th- 6th post-operative day once pain is minimal, sitting with back rest is allowed after 2 weeks but long trips avoided upto 3 months. Isometric abdominal exercises started after suture removal with spine extension and isotonic exercise of leg with lumbosacral belt for 3 months and forward bending is restricted for 12 weeks.

Patients with jobs requiring much walking without lifting weights are allowed to work after one month. Patients with jobs requiring prolonged sitting are allowed to go for work after 2 months rest. Patients with jobs requiring heavy labour are advised to switch to light work. Patients regularly assessed at 6 weeks, $3^{\text {rd }}$ month and $6^{\text {th }}$ month and in particular, graduated exercise programs, are also useful adjuncts to antiinflammatory approaches. ${ }^{[10]}$

\section{Indication for surgery}

The key to good results in disc surgery is appropriate patient selection. The optimal patient is one with predominant (if not only) unilateral leg pain extending below the knee that has been present for at least 6 weeks. The pain should have been decreased by rest, anti-inflammatory medication, or even epidural steroids but should have returned to the initial levels after a minimum of 6 to 8 weeks of conservative care ${ }^{[7,8]}$

\section{Follow-ups}

Table 2: Follow Up Timing after Interventions

\begin{tabular}{|c|c|}
\hline Follow Ups & Duration (After Conservative/Epidural Steroid/Surgery(Disectomy) \\
\hline First & Immediate Post Op \\
\hline Second & At 15 Days \\
\hline Third & 1 Month \\
\hline Fourth & 3 Months \\
\hline Fifth & 6 Months \\
\hline
\end{tabular}


Parameter for Evaluation

1. Visual analogue score for leg pain and back pain
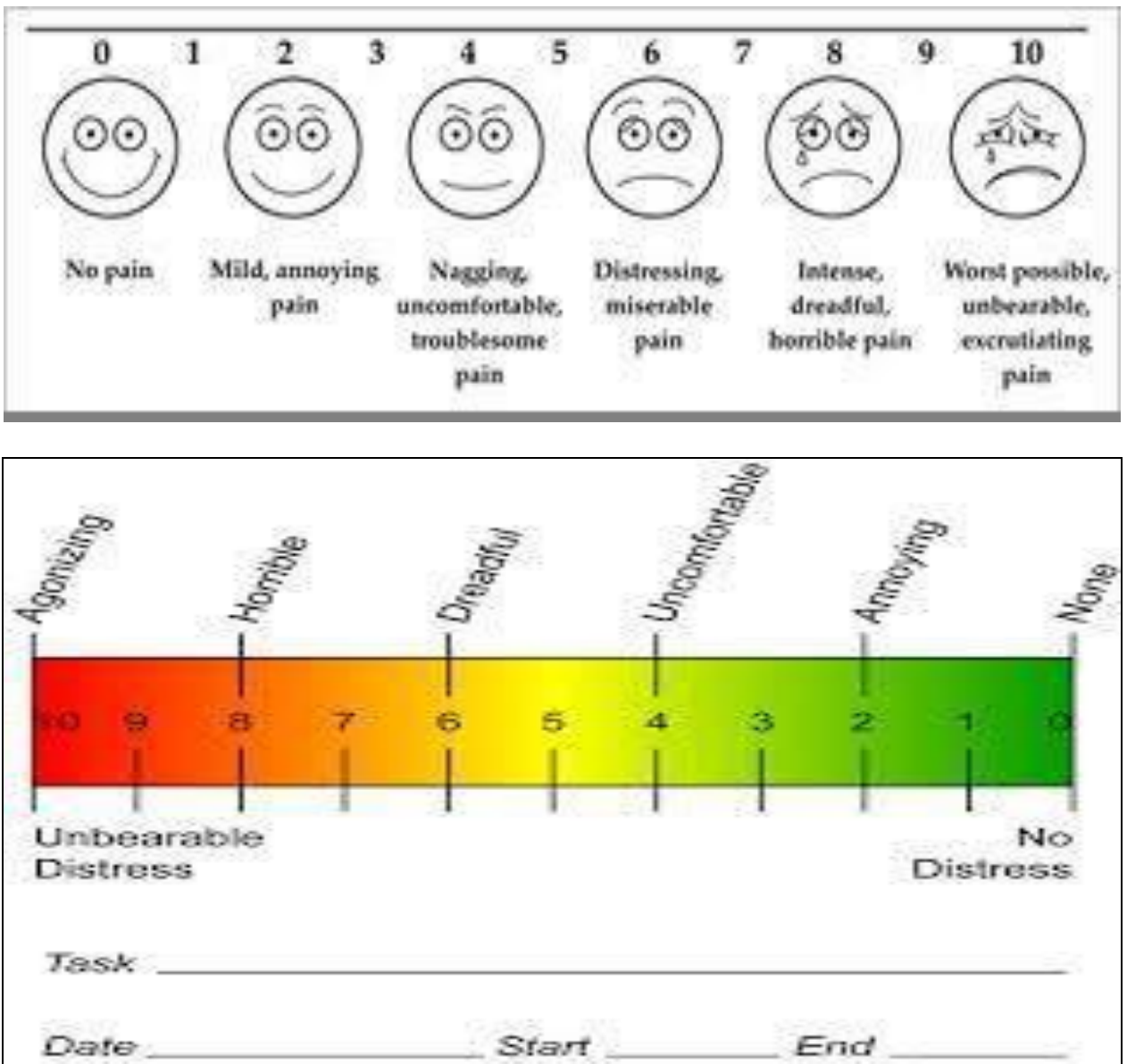

Fig 1: VAS Analog Score

2. Roland -Morris Disability Questionnaire ${ }^{[5]}$ : 25 Question were asked to each patient.

3. Owestry Disability Index (Odi Score) ${ }^{[6]}: 10$ sections each section containing 6 questions.

Interpretation: Add up your points to calculate your level of disability:

Point total $/ 50 \times 100=\%$ disability

For example: Current level of disability was calculated as follows:

\section{$14 / 50 \times 100=28 \%$}

\section{ODI scoring:}

1. 0 to $20 \%$ : Minimal disability

2. 21 to $40 \%$ : Moderate disability

3. 41 to $60 \%$ : Severe disability

4. 61 to $80 \%$ : Crippled

5. 81 to $100 \%$ : These patients are either bed bound or exaggerating their symptoms.

Improvement in ODI score at last follow-up:

\begin{tabular}{|c|c|}
\hline Improvement In ODI Score & Outcome \\
\hline$>80 \%$ improvement \& return to same work & Excellent \\
\hline $60-80 \%$ & Good \\
\hline $20-60 \%$ & Fair \\
\hline$<20 \%$ & Poor \\
\hline
\end{tabular}

\section{Statistical Analysis}

Categorical variables were presented in number and percentage (\%) and continuous variables were presented as mean \pm SD and median. Normality of data was tested by Kolmogorov-Smirnov test. If the normality is rejected then non parametric test were used.

\section{Statistical tests were applied as follows}

1. Quantitative variables were compared using ANOVA/Kruskal Wallis Test (when the data sets were not normally distributed) between the three groups and paired $\mathrm{T}$ test/Wilcoxon test was used to compare across follow up.

2. Qualitative variables were compared using Chi-Square test. A $p$ value of $<0.05$ was considered statistically significant.

3. The data was entered in MS EXCEL spreadsheet and analysis was done using Statistical Package for Social Sciences (SPSS) version 21.

\section{Result}

In our study highest incidence of lumbar PIVD was seen in age group 31-40 with $30 \%$ of patients followed by $41-50$ age group accounting $34 \%$ of cases. Most of patients were housewives and sedentary workers. In our study $57.65 \%$ were male, with $42.35 \%$ patients being female. L4-L5 PIVD was commonest in our study with around $52.94 \%$ of patients, followed by L5-S1 PIVD accounting for $21.18 \%$ of cases. In most cases precipitating factor was occupational strain. 
Patients were evaluated, with detailed history and thorough clinical examination, with respect to radiculitis, neurology and root tension signs. In most patients straight leg raisng test was positive, patients were evaluated at post op 15 days, 1 months, 3 months and 6 months with respect to previous examination findings short term outcome over a period of six months, good (60-80\% improvement in ODI) to excellent (>
$80 \%$ improvement in ODI) outcome is seen in $94 \%$ of surgically treated patients, whereas only $81 \%$ of patients treated with epidural steroid were to having good to excellent results but in conservatively treated group only $12 \%$ of patients had good to excellent outcome. Around $88 \%$ of conservatively treated patients had fair outcome.

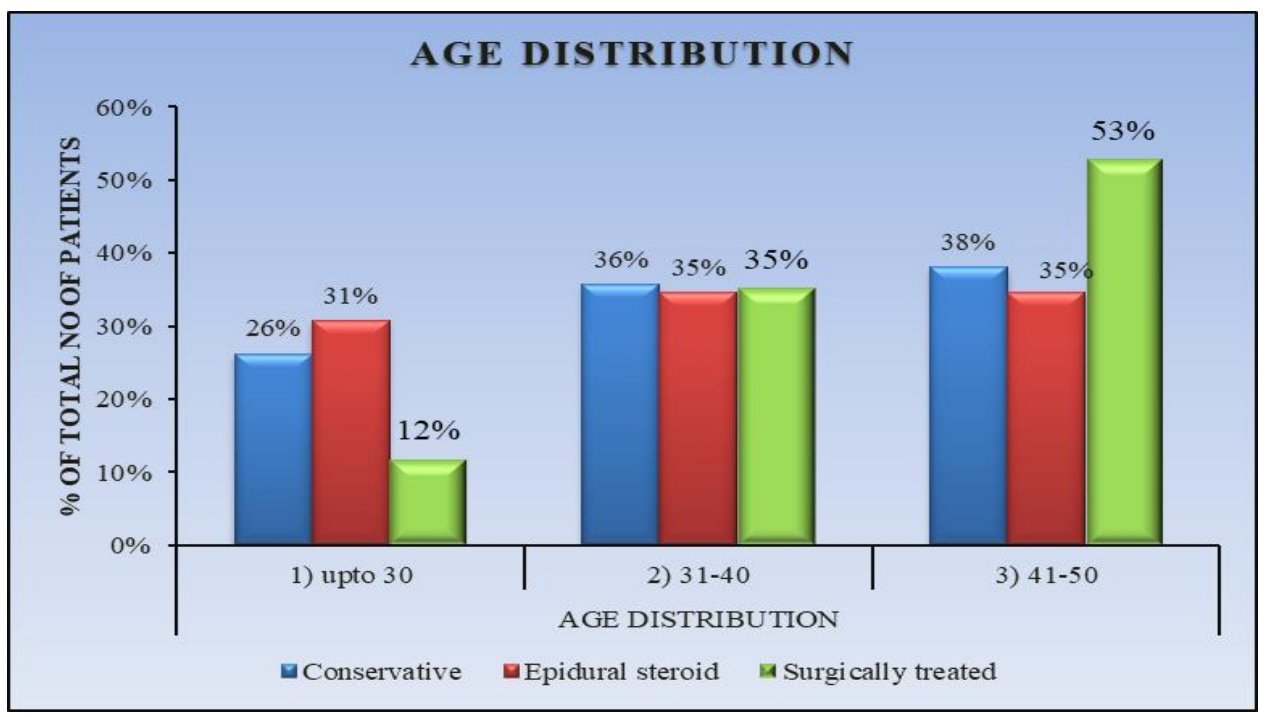

Graph 1: Age Distribution

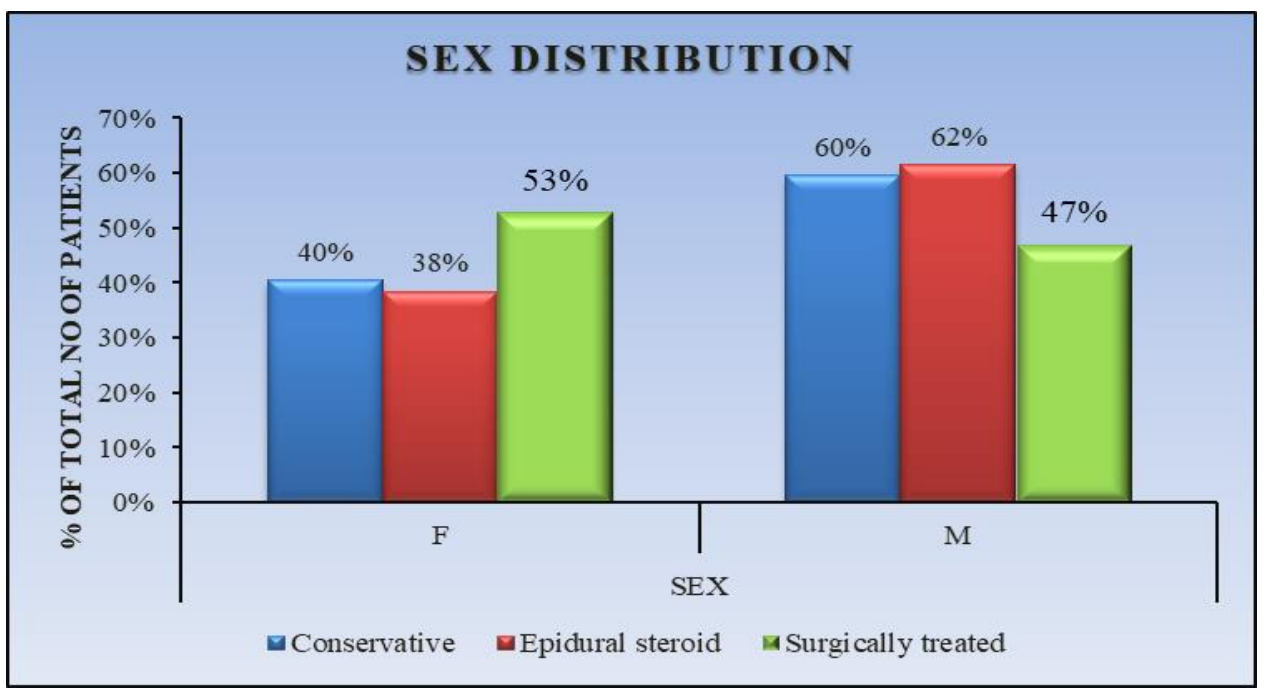

Graph 2: Sex Distribution

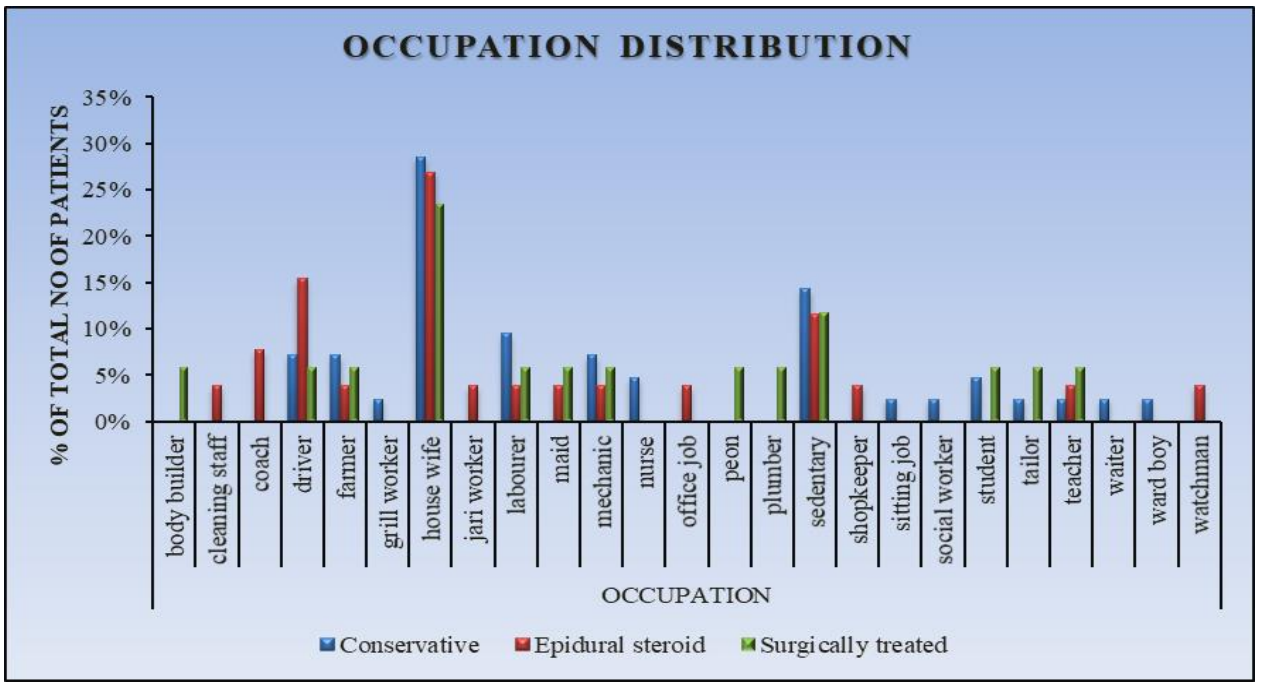

Graph 3: Occupation Distribution 


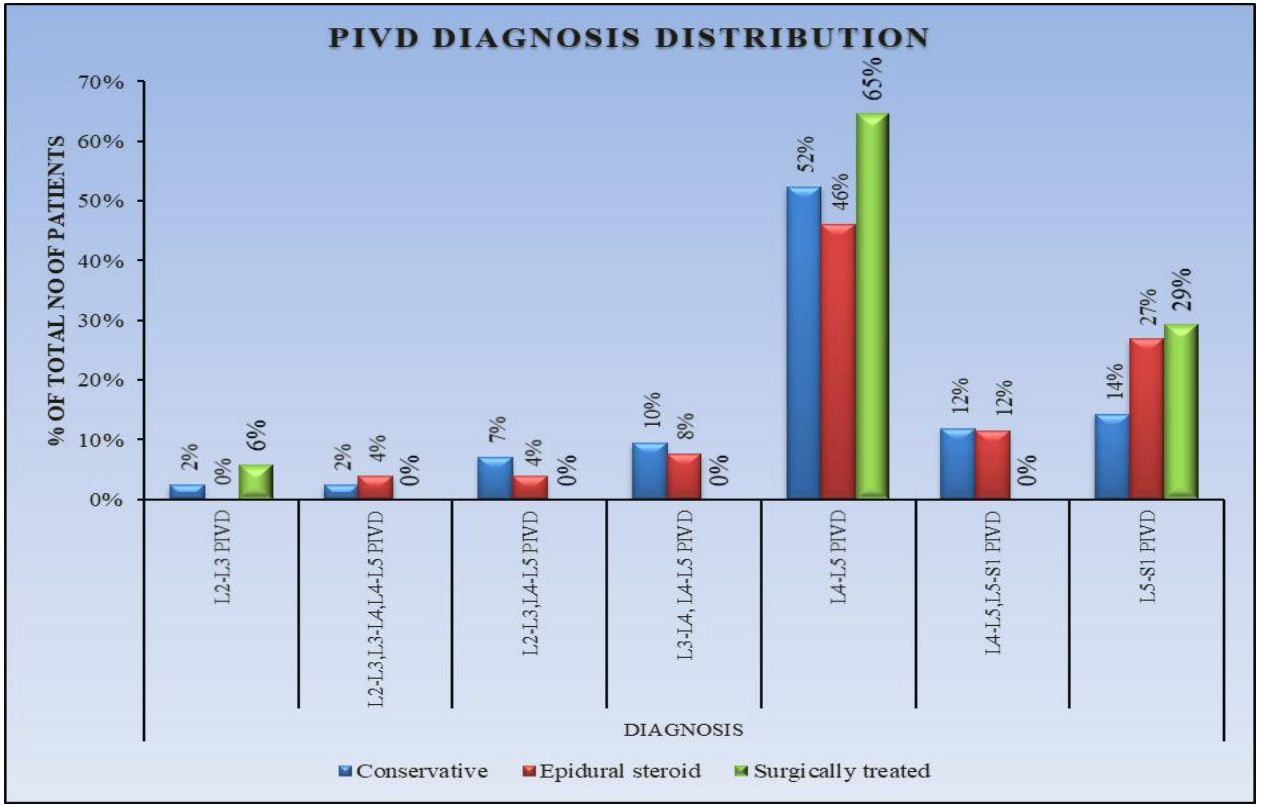

Graph 4: Pivd Diagnosis Distribution

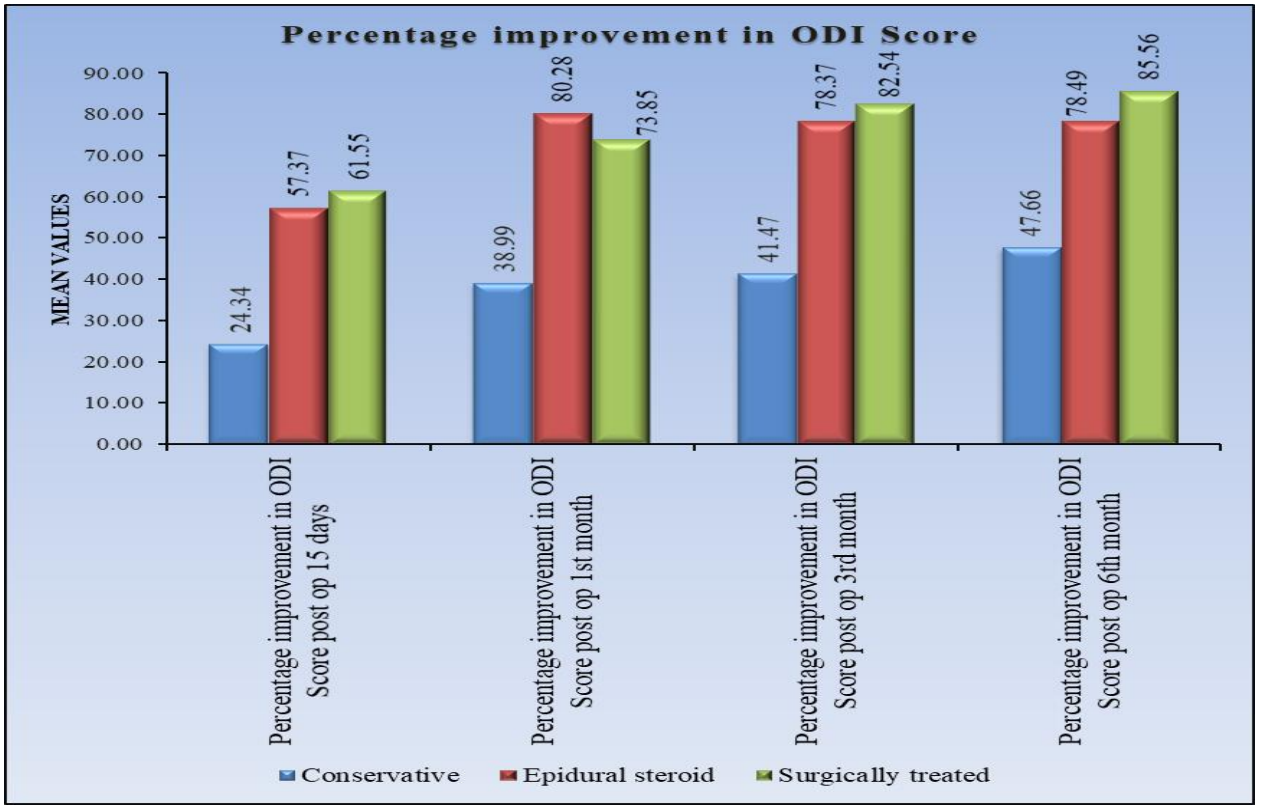

Graph 5: Percentage Improvement in Odi

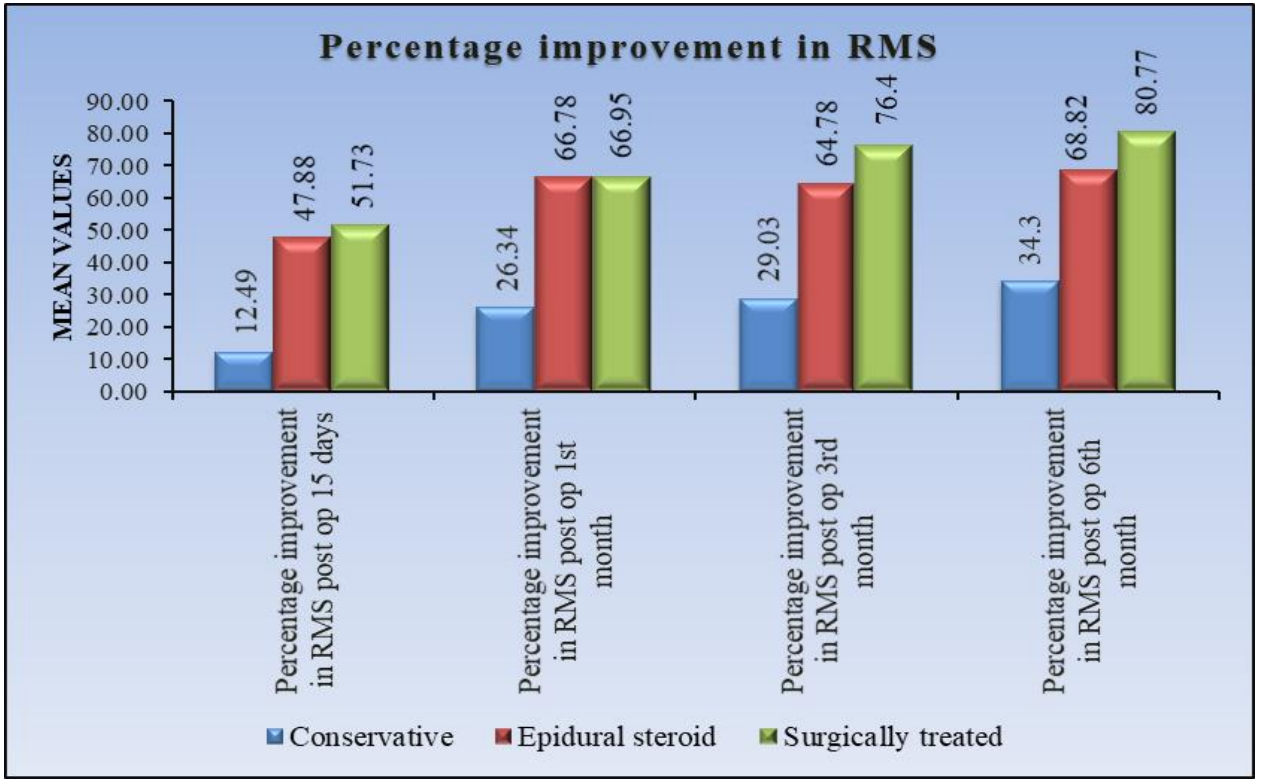

Graph 6: Percentage Improvement In Rms

$$
\sim 41 \sim
$$




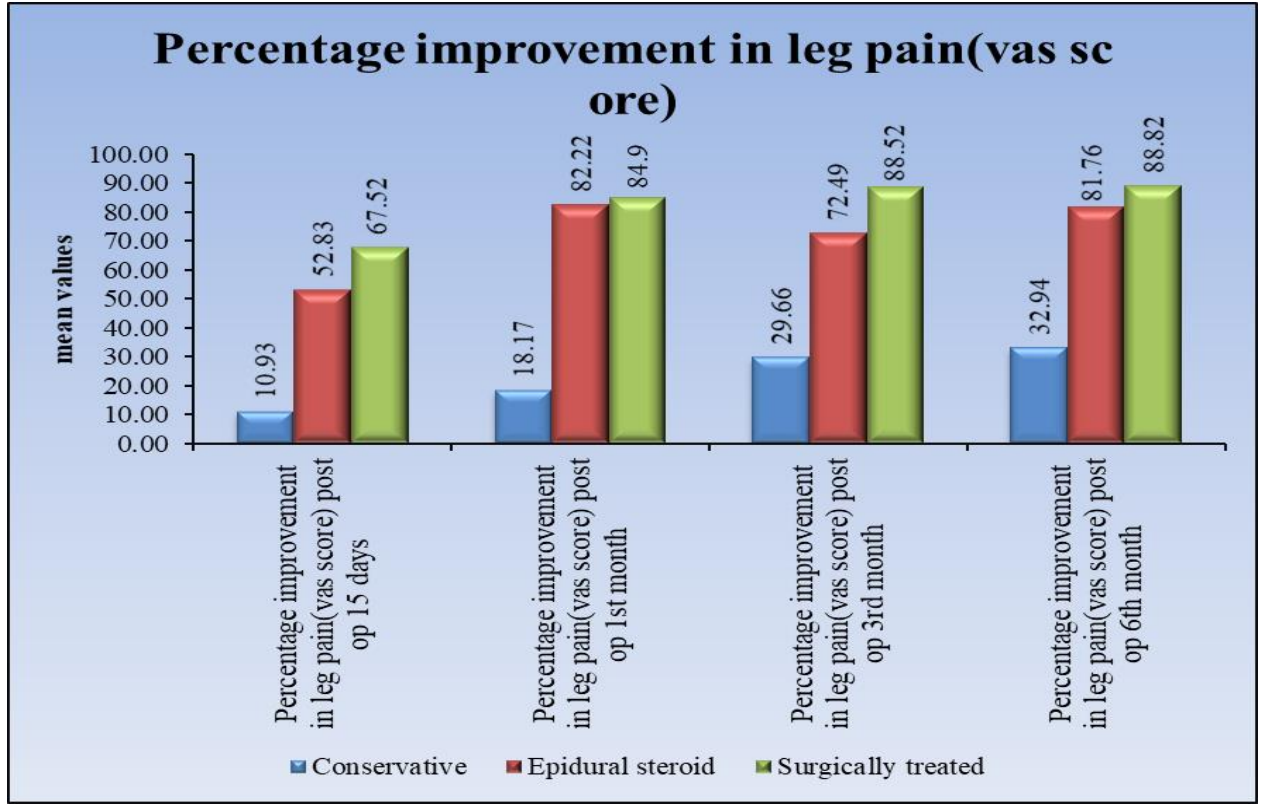

Graph 7: Percentage Improvement in Leg Pain (Vas Score) Post Op

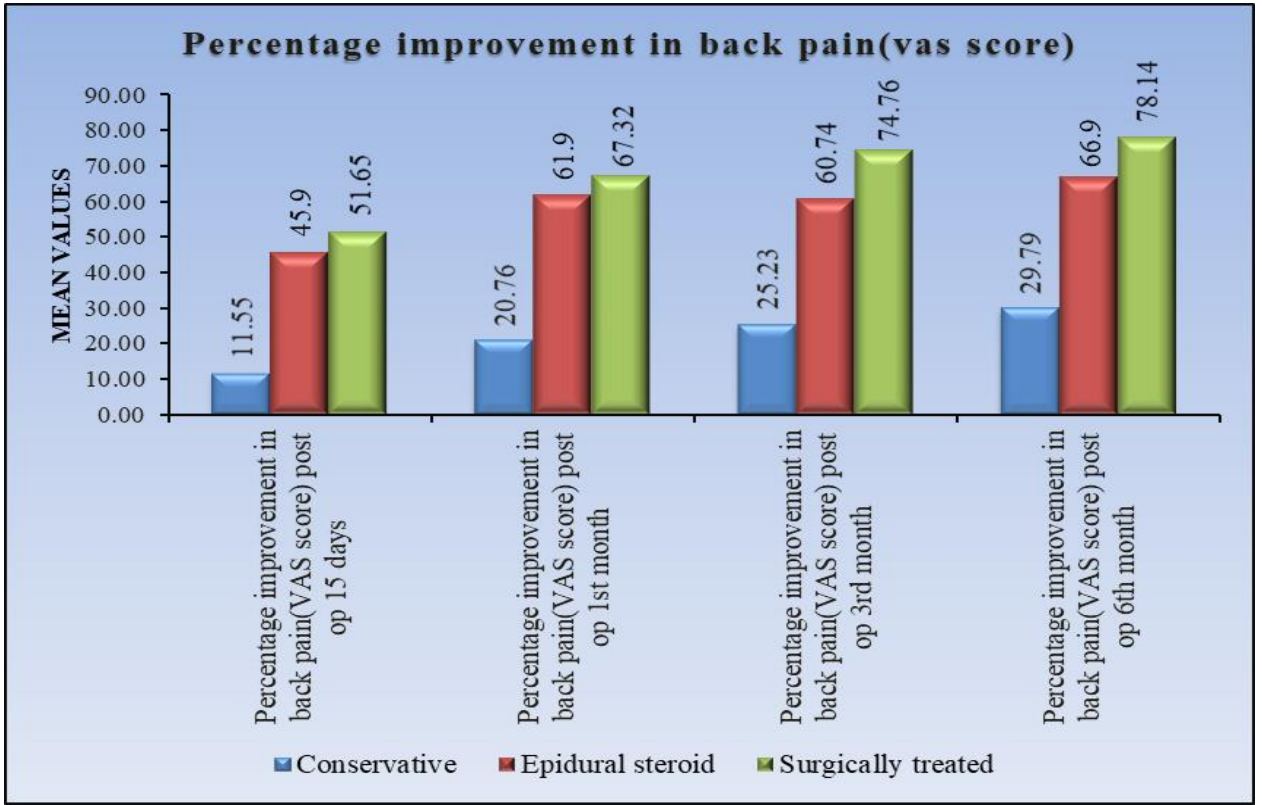

Graph 8: Percentage Improvement in Back Pain (Vas Score) Post Op

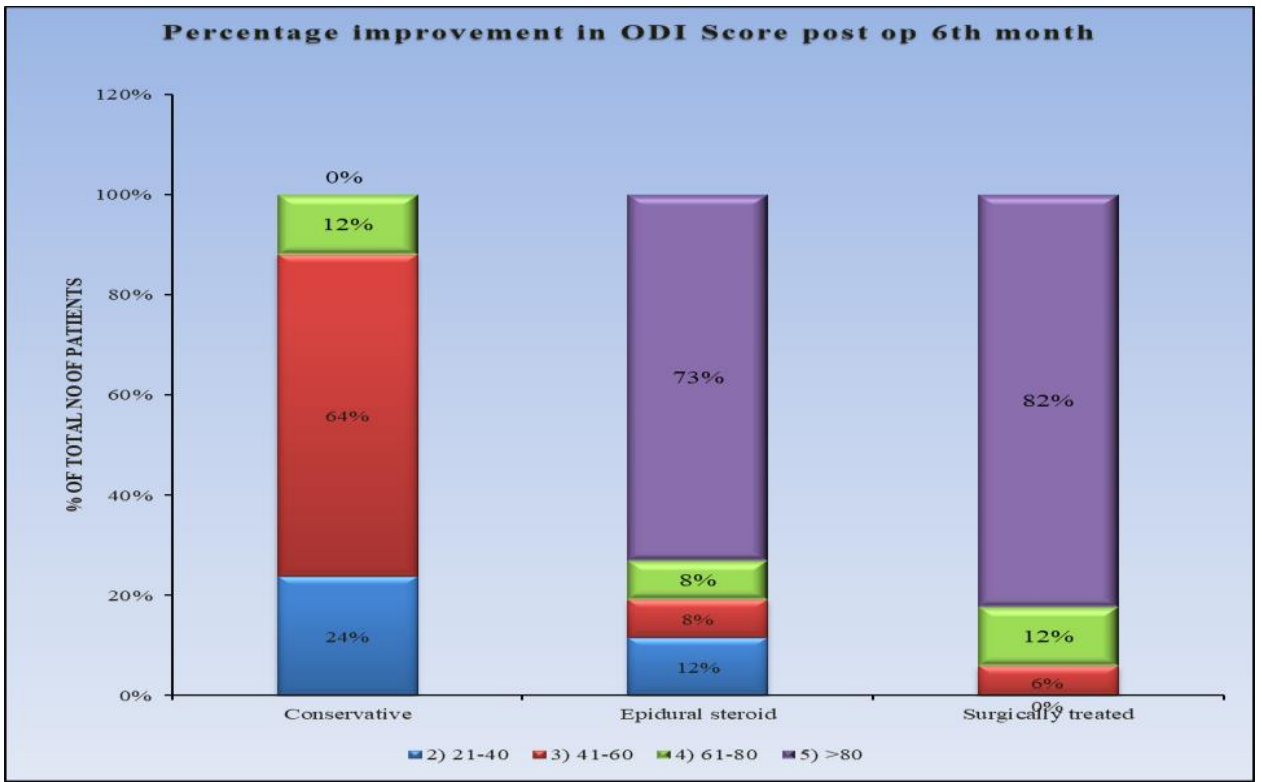

Graph 9: Percentage Improvement in ODI Score Post Op 6th Month $\sim 42 \sim$ 


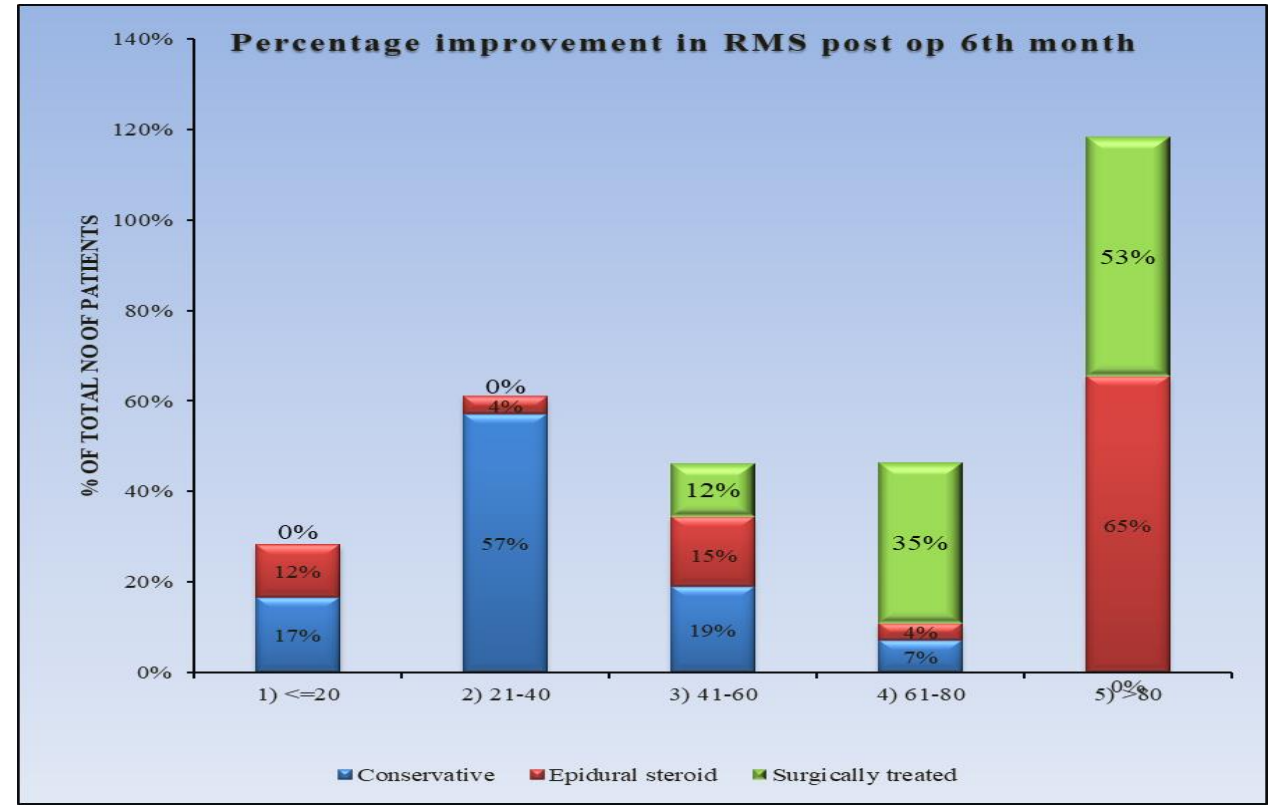

Graph 10: Percentage Improvement in Rms Post Op 6th Month

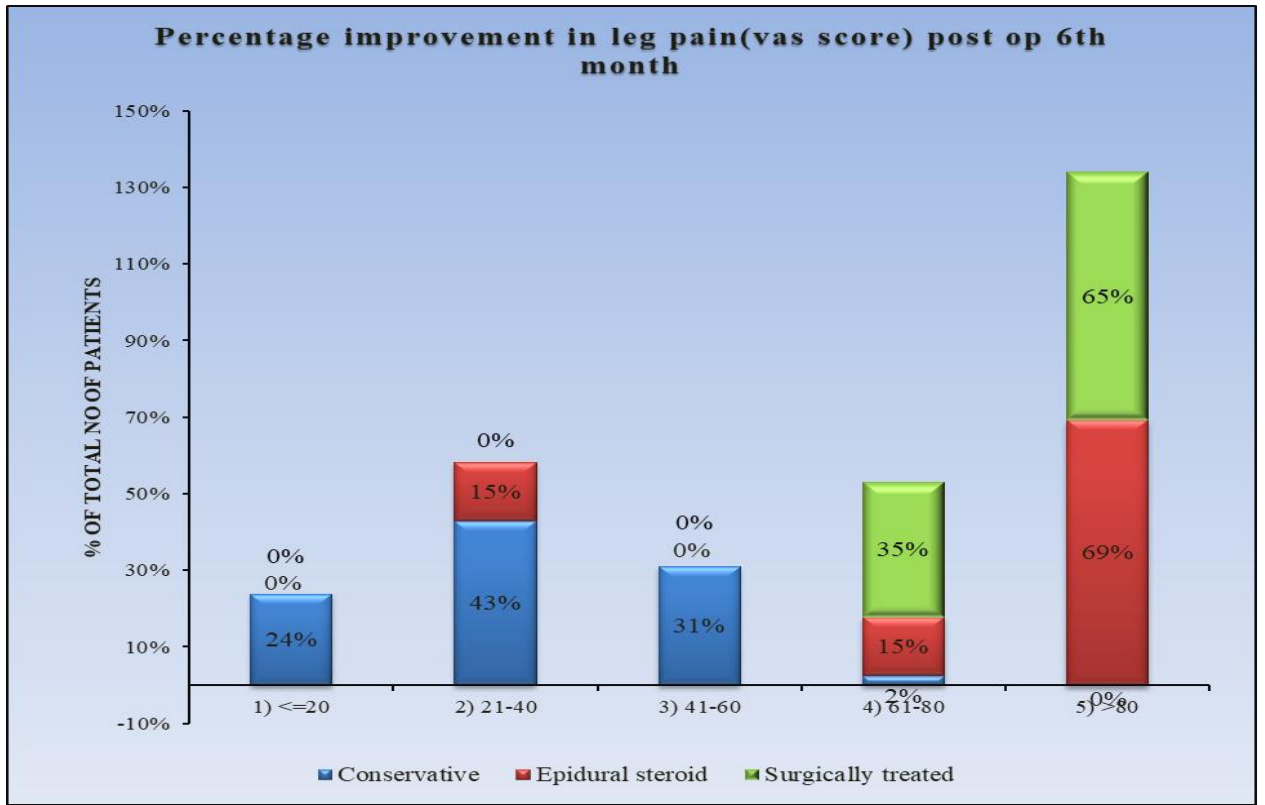

Graph 11: Percentage Improvement In Leg Pain (Vas Score) Post Op 6th Month

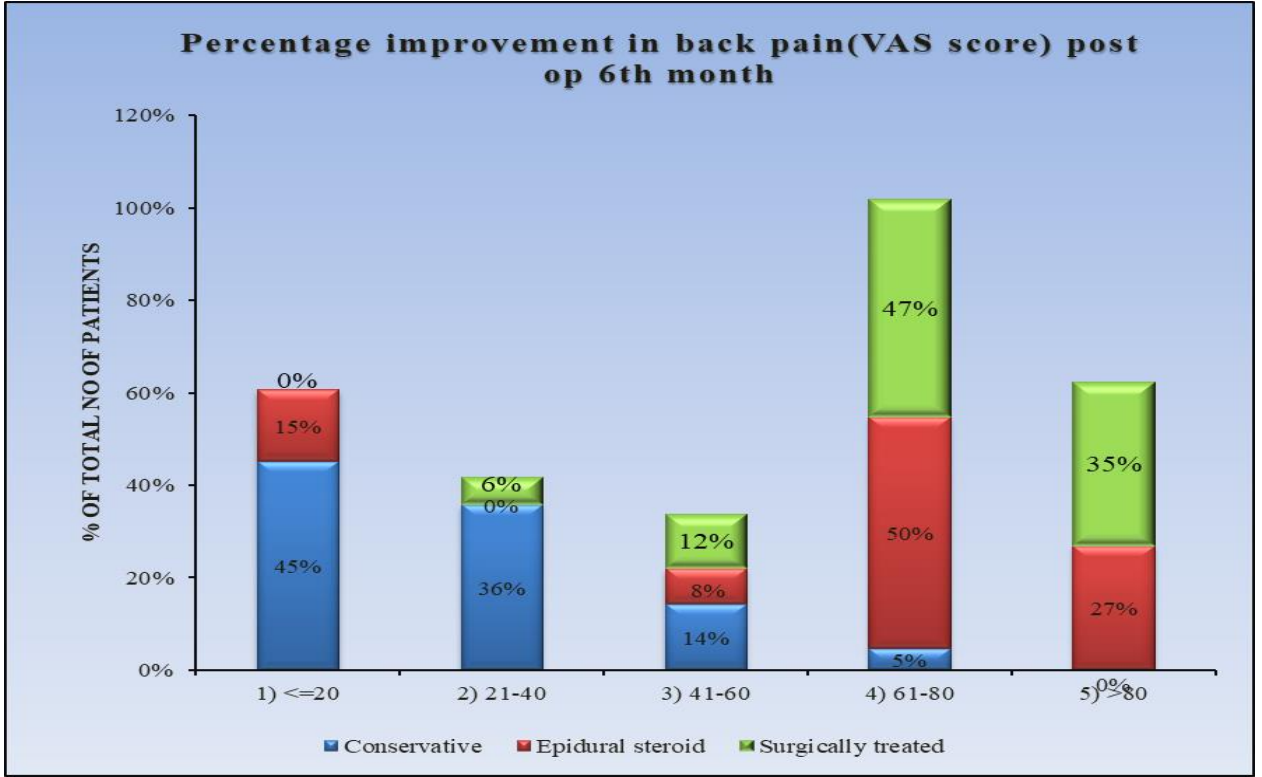

Graph 12: Percentage Improvement in Back Pain (Vas Score) Post Op 6th Month $\sim 43 \sim$ 


\section{Discussion}

Majority of case of lumbar prolapsed intervertebral disc respond to conservative line of management. Hence its safe to observe wait and watch policy even for massive disc without cauda equine. Short term outcome of discectomy for PIVD is favourable as compared to conservative at end of six months, however in studies of Weber et al. ${ }^{[11]}$ and sport trial $2006^{12}$ at 4 years outcome of surgical management is still better than conservative management although statistical significance decreases. At 5 year both group having similar improvement. ${ }^{11}$ Epidural steroid offers promise for temporary relief for most patient for a time period of 3-6 month with many patient requiring repeat injection at variable time interval ${ }^{[13-15]}$. For now many consider epidural steroid as terminal step in conservative management before surgery is offered to patients.With surgery it is leg pain i.e. sciatica or radiculitis that improves better than back pain. Age, sex, occupation had no bearing on outcome of various managements. Protruded disc do regress with time, transligamentous disc showed greater chances of regression, various study show $60 \%$ volume decrease by 1 year time. However subligamentous disc do not regress much (only $17 \%$ case showing regression with time). ${ }^{[16]}$

\section{Clinical Pictures}

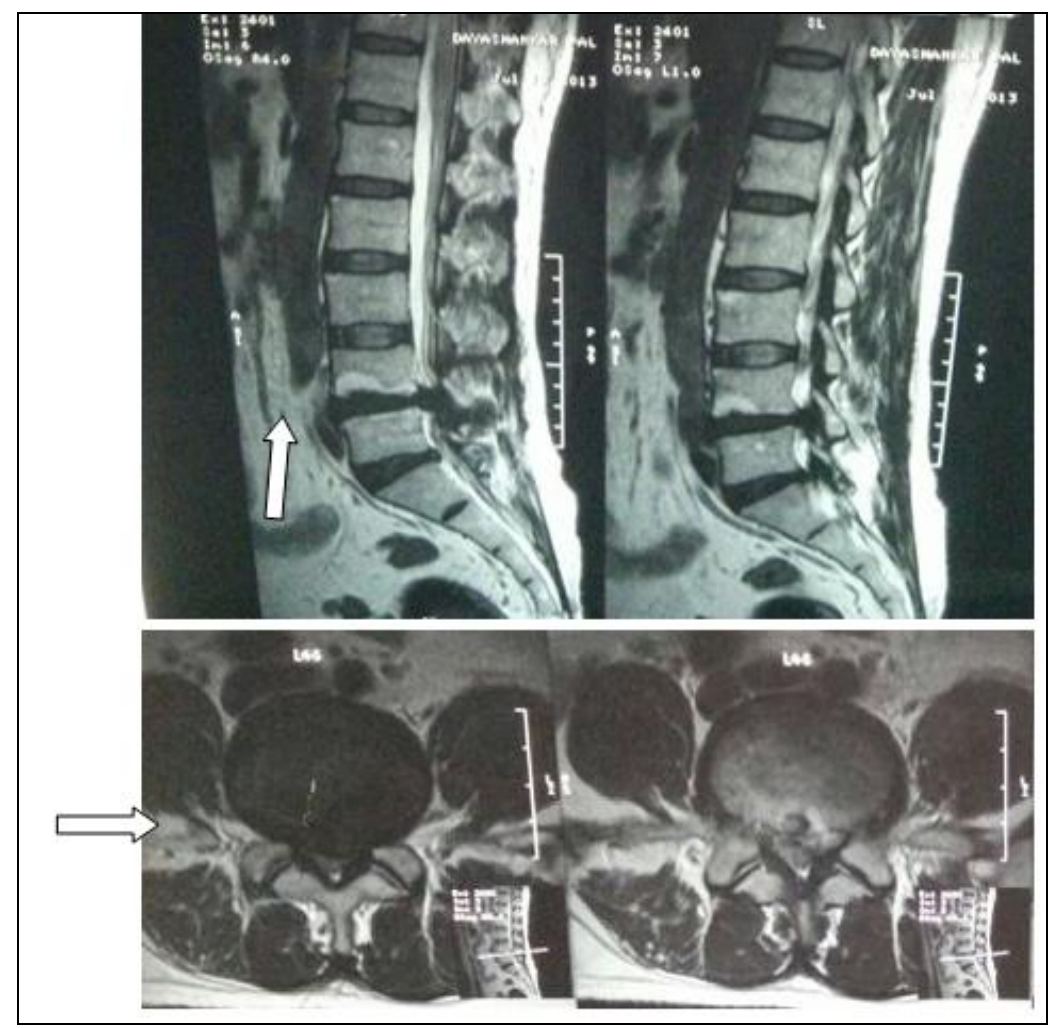

Fig 2: MRI of Lumbar Prolapsed intervertebral disc

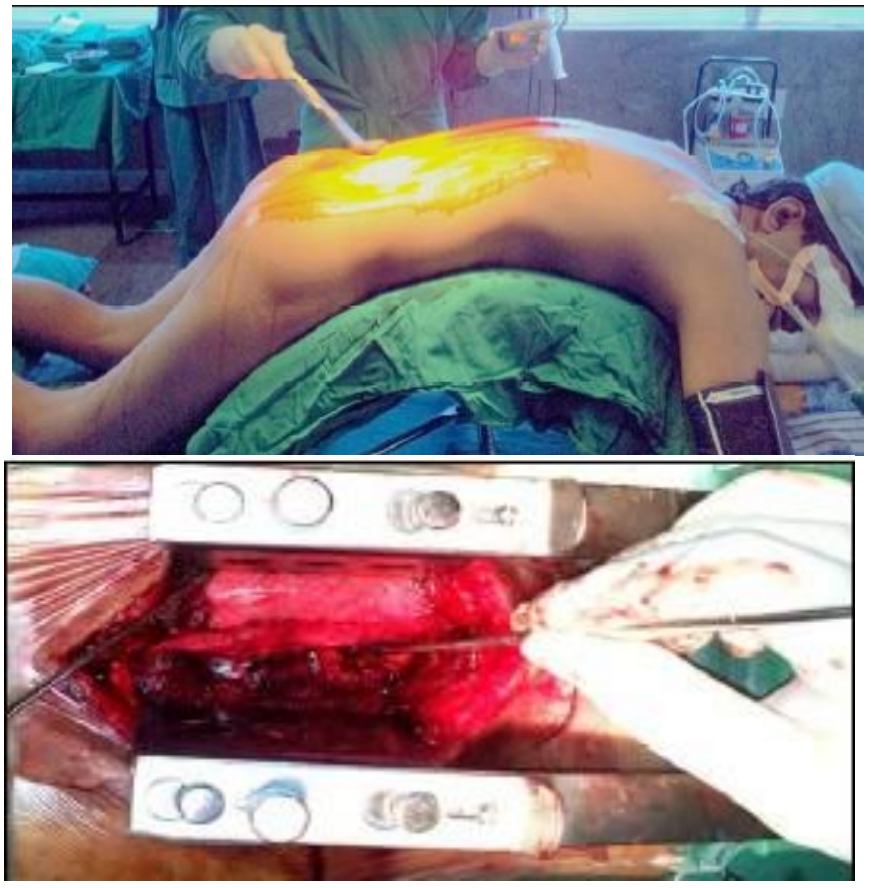

Fig 3: Operative Pictures

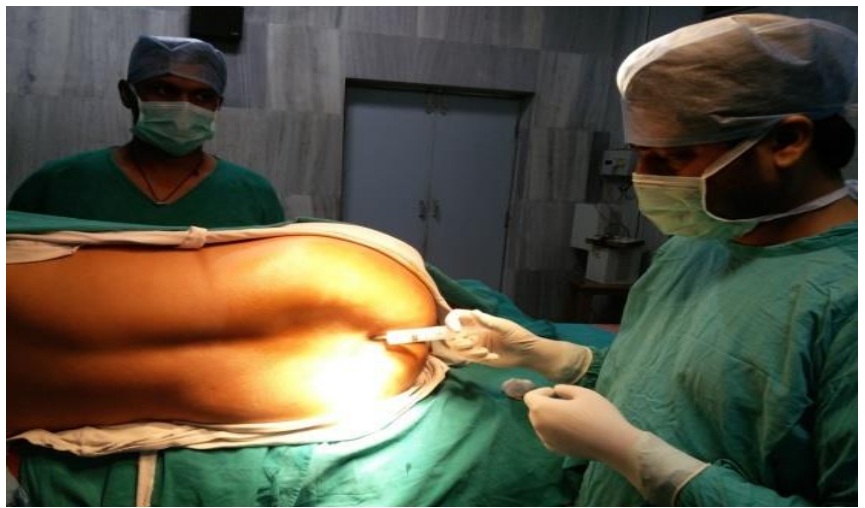

Fig 4: Epidural steroids injection

\section{Conclusion}

Short term outcome of discectomy for PIVD is favorable as compared to conservative treatment. Epidural steroid offers promise for temporary relief with many patient requiring repeat injections at variable time interval. However larger study with longer duration of study is needed for evaluation. 


\section{References}

1. Andersson G. Epidemiological features of chronic lowback pain. Lancet. 1999; 354:581-585.

2. Papageorgiou A, Croft P, Ferry S, Jayson MIV, Silman A. Estimating the prevalence of low back pain in the general population. Spine. 1995; 20:1889-1894.

3. Smith L. Enzyme dissolution of nucleus pulposus in humans. JAMA 1964; 187:137.

4. Prevalence of lumbar disc herniation and disc degeneration in asymptomatic Indian subjects: An MRI based study Dr. Sasi Kuppuswamy, Dr. James C George and Dr. Mili Chemmanam DOI: https://doi.org/10.22271/ortho.2017; 3.i4e.50

5. Fairbank JCT, Couper J, Davies JB, O'Brian JP. The Oswestry low back pain disability questionnaire. Physiotherapy. 1980; 66:271-3.

6. Roland MO, Morris RW. A study of the natural history of back pain. Part 1: Development of a reliable and sensitive measure of disability in low back pain. Spine. 1983; 8:141-144

7. Rothoerl RD, Woertgen C, Brawanski A. When should conservative treatment for lumbar disc herniation be ceased and surgery considered? Neurosurg Rev. 2002; 25:162-5

8. Raymond J Gardocki, Ashley L Park. Degnerative disorders of the thoracic and lumbar spine. In: Azar FM, Beaty JH, Canale ST (Eds). Campbell's Operative Orthopaedics. $13^{\text {th }}$ ed. Canada. 2017, 1833.1922.

9. Wong DA, Transfeldt E. Macanab Backache. $4^{\text {th }}$ ed. Philedelphia: Lippincott Williams \& Wilkins, 2007.

10. Yeung CA. Arizona Institute for Minimally Invasive Spine Care, Phoenix, Arizona. J Clin Neurosci. 2003; 10(2):231-5.

11. Weber $\mathrm{H}$ et al. Lumbar disc herniation - A controlled prospective study with ten years of observation, Spine. 1983; 8:131-140.

12. Weinstein JN, Tosteson TD, Lurie JD, Tosteson AN, Hanscom B et al. Surgical vs nonoperative treatment for lumbar disk herniation: the Spine Patient Outcomes Research Trial (SPORT): A randomized trial. JAMA. 2006; 296:2441-50

13. Manchikanti L, Benyamin RM, Falco FJ, Kaye AD, Hirsch JA. Do epidural injections provide short- and long-term relief for lumbar disc herniation? A systematic review. Clin Orthop Relat Res. 2015; 473:1940-1956.

14. Singam PA, Dhakate RV, Yelurkar SS, Gosavi NS. Use of epidural steroids in cases of low back pain and sciatica: A prospective observational study. International J. of Healthcare and Biomedical Research. 2014; 2(3):98104.

15. Buchner M, Zeifang F, Brocai DR, Schiltenwolf M. Epidural corticosteroid injection in the conservative management of sciatica. Clin Orth Rel Res. 2000; 375:149-156.

16. Bush K, Cowan N, Katz DE, Gishen P. The natural history of sciatica associated with disc pathology. A prospective study with clinical and independent radiologic follow-up. Spine. 1992; 17:1205-12. 